\title{
Pipefish foraging: effects of fish size, prey size and altered habitat complexity
}

\author{
Clifford H. Ryer* \\ Division of Fisheries and Biological Science, Virginia Institute of Marine Science, School of Marine Science, College of \\ William and Mary, Gloucester Point, Virginia 23062, USA
}

\begin{abstract}
Laboratory experiments determined the effects of 2 levels of habitat complexity upon pipefish Syngnathus fuscus foraging for amphipods. Habitats were composed of equal densities of either narrow (low complexity) or wide (high complexity) leafed artificial seagrass. Response to habitat as measured by rate of encounter with amphipods, probability of attack after encounter, probability of success after attack, and overall rate of amphipod consumption - was determined for combinations of 2 fish size classes and 3 amphipod size classes. Small fish did not respond to changes in habitat complexity, while large fish did. Large fish encountered fewer amphipods in the high than in the low complexity habitat. In general encounter rate increased with amphipod size. Large fish attack probability was negatively related to amphipod size in the narrow leaf habitat, but positively related to amphipod size in the wide leaf habitat. Small fish attack probability was negatively related to amphipod size in both habitats. Success was negatively related to prey size and greater for large than for small fish, and showed no overall effect of habitat. The position that amphipods occupy in the structure of vegetation in part determines their vulnerability to predation, a criterion by which pipefish appear to select prey. In this respect pipefish behavior is flexible, allowing adjustment of foraging tactics to match habitat constraints. Results suggest that relative sizes of predator and prey are important factors in determining the effect of structural complexity upon predator-prey dynamics.
\end{abstract}

\section{INTRODUCTION}

Predation can be a major determinant of the abundance and distribution of species, as well as influencing community structure (Paine 1966). In the absence of some spatial or temporal heterogeneity, predator-prey systems may be unstable, as exemplified by simple laboratory systems where both prey and predator go extinct (Gause 1934). Numerous physical aspects of aquatic habitats provide structural complexity: substrate (Lipcius \& Hines 1986, Smith \& Coull 1987), litter (Ware 1972), worm-tubes (Bell \& Coen 1982), emergent macrophytes (van Dolah 1978), and submerged macrophytes (Crowder \& Cooper 1982, Stoner 1982, Coull \& Wells 1983). The effect of artificial structure upon predator-prey interaction has also been examined (Heck \& Thoman 1981, Marinelli \& Coull 1987, Russo 1987). With few exceptions (Marinelli \& Coull 1987) predator efficiency decreases with increasing habitat

- Present address: Hatfield Marine Science Center, Oregon State University, Newport, Oregon 97365, USA complexity, and there may be a threshold above which efficiency decreases abruptly (Coull \& Wells 1983). In addition, prey density usually increases with increasing habitat complexity, resulting in peak predator feeding and growth rates at intermediate complexities (Crowder \& Cooper 1982).

Mechanistic foraging models that account for visual reactive field volumes (Werner \& Hall 1974), prey visibility (Zaret \& Kerfoot 1975), prey motion (Zaret 1980a) and the apparent size of prey (O'Brien et al. 1976) have been developed for zooplanktivorous fish. Similar models which account for the visual and physical inhibitory effects of vegetation or other structures have yet to be developed. A prerequisite to the development of such models is a more detailed knowledge of precisely how structure alters the mechanisms of predator-prey interaction.

The northern pipefish Syngnathus fuscus is a common inhabitant of vegetated shallows along much of the North American east coast (Dawson 1982). Prior field and laboratory studies of pipefish provide background data on foraging behavior and prey selec- 
tion (Ryer \& Orth 1987). Here I examine pipefish amphipod interactions ( 2 fish sizes and 3 amphipod sizes) at 2 levels of habitat (artificial seagrass) complexity. Various investigators have used different measures of complexity in vegetated habitats: biomass (Orth 1977, Stoner 1980), shoot/blade density (Homziak et al. 1982), surface area (Stoner \& Lewis 1985), and surfaceto-volume ratio (Coull \& Wells 1983). I have observed gammarid amphipods to preferentially occupy the spaces between the basal portions of artificial seagrass blades, apparently reducing their conspicuousness and vulnerability to pipefish. I reasoned that changing the width of grassblades would affect the ability of pipefish to visually locate amphipods, as well as their ability to extract amphipods once encounter had occurred. I therefore define habitat complexity in terms of leaf width: narrow leaf $=$ low complexity, wide leaf $=$ high complexity

The approach of this study was to divide predator efficiency into separately measurable components or mechanisms: encounter, attack, and success. I predicted that change in grassblade architecture from wide to narrow leaves would have separate and independent effects upon these mechanisms. (1) Encounter rates would be higher in low complexity vegetation, increase with amphipod size, and be greater for large fish, for the following reasons. Amphipods should be more visible positioned between narrow as opposed to wide leaves. Also, the lowered total vegetation surface area of narrow leaves should impinge less than wide leaves upon the distance at which amphipods can be detected. Larger amphipods will be more conspicuous positioned between grassblades, making them easier to detect than small amphipods. Larger prey can also be seen at greater distance, as predicted by the Reactive Field Volume Model (Werner \& Hall 1974). Large fish, having larger eyes and greater visual acuity at distance (Northmore et al. 1978), should have larger reactive fields for prey than small fish. (2) Attack probability, once an encounter has occurred, would be higher in the low complexity habitat, higher for large fish, and negatively related to amphipod size. Narrow leaves should provide less protection, making amphipods more vulnerable. Amphipods also appear to gain some degree of protection from predation through increased size, and in preliminary experiments I observed that pipefish were less likely to attack amphipods that were large, as opposed to small, relative to themselves (unpubl. data). (3) Probability of successful consumption of an amphipod after initiation of attack would be comparable across habitat complexities, higher for large fish, and negatively related to amphipod size. These predictions essentially follow from those on attack probabilities, which should increase predator efficiency by minimizing unsuccess- ful attacks. This should eliminate or decrease differences in success probabilities between habitat complexities by eliminating attacks which, due to the amphipods positioning in the vegetation, would have a low probability for success. This should result in sizerelated predatory capabilities for pipefish, and escape capabilities for amphipods, becoming the principle determinants of success.

These mechanisms of pipefish-amphipod interaction should give rise to decreasing predator efficiency, in this case the rate at which amphipods are consumed by pipefish, with increased habitat complexity, an effect that has been widely observed in other aquatic and marine predator-prey system.

\section{MATERIALS AND METHODS}

Animal collection and maintenance. Pipefish were obtained from eelgrass Zostera marina meadows located at the mouth of the York River, in the lower Chesapeake Bay, USA. Fish were held in static, subsand-filtered $38 \mathrm{l}$ aquaria, with a uniform density $(60$ shoots, 4 leaves shoot ${ }^{-1}$, mean leaf length $=11 \mathrm{~cm}$ ) of $5 \mathrm{~mm}$ wide artificial eelgrass (polypropylene ribbon). Pipefish were held for a minimum of $1 \mathrm{wk}$ prior to experimentation and daily fed a mixed diet of gammarid amphipods and Artemia nauplii.

Two Gammarus spp. were used interchangeably as prey: $G$. mucronatus, an inhabitant of eelgrass and algal communities (Fredette \& Diaz 1986), and $G$. palustris, an intertidal marsh inhabitant (van Dolah 1978). These amphipods are morphologically very similar, and like most free-living vegetation-dwelling amphipods, are highly thigmotactic (Nagle 1968, van Dolah 1978). Preliminary observations indicated that both preferred to occupy spaces between basal portions of grassblades, demonstrated comparable activities and movements, and interacted with pipefish in identical manners. I therefore assumed that prey species would have no effect upon experimental outcomes. Amphipods were kept in static, subsand-filtered aquaria and fed frozen chopped spinach. Pipefish and amphipods were kept at temperatures of 24 to $25^{\circ} \mathrm{C}$ and experienced natural photoperiod.

Experimental design and procedures. A 3-factor factorial design was employed: 2 levels of habitat complexity, 2 fish size classes, and 3 amphipod size classes. All trials were conducted in aerated static $38 \mathrm{l}$ aquaria with sand substrate, artificial eelgrass, an overhead aquarium light to provide consistent illumination and filtered $(1 \mu \mathrm{m})$ York River water (salinity range 16 to $24 \mathrm{ppt}$ ). The high complexity habitat treatments consisted of artificial eelgrass as described above. This shoot density (480 shoots $\mathrm{m}^{-2}$, or 1920 blades $\mathrm{m}^{-2}$ ) 
provided enough habitat complexity to keep amphipods from congregating in aquarium corners, but still allowed detailed behavioral observations. While this density is low compared to seasonal highs for Zostera marina (ca 3000 shoots $\mathrm{m}^{-2}$ in March and April; Orth \& Moore 1986), it is representative of intermediate densities encountered in the lower Chesapeake Bay during summer (Heck \& Thoman 1981). The low complexity habitat consisted of an equal number of identically constructed shoots, but made with $1.7 \mathrm{~mm}$ wide ribbon. Thus, the surface area of artificial vegetation in the low complexity treatments was $33 \%$ of that in the high complexity treatments.

Fish size classes were small $(110$ to $130 \mathrm{~mm})$ and large (180 to $200 \mathrm{~mm}$ total length). No fish was used more than once within a cell of the factorial design; due to limited supply, some fish were used more than once between cells ( 7 fish used twice). Amphipod size classes were small (mean size $=4.8 \mathrm{~mm}$ ), medium $(6.1 \mathrm{~mm})$, and large $(7.0 \mathrm{~mm}$ total length from base of 2nd antennae to the tip of uropods). Amphipods were sorted by mechanical sieving. By repeated sieving and discarding of amphipods from intervening sieves, overlap between classes was eliminated. Amphipods showed no adverse effects resulting from the sieving process. No a priori data on the variance of dependent variables was available, and the extent of replication was determined by logistical constraints. Six trials for each combination of habitat, fish size, and prey size were conducted.

Trials were run during the morning with a maximum of 8 per day. At $24 \mathrm{~h}$ prior to experimentation, fish were isolated in experimental aquaria (1 fish aquarium ${ }^{-1}$ ) without prey, assuring a uniform period without access to food. At $12 \mathrm{~h}$ prior to experimentation 50 amphipods were added to each aquarium and immediately covered with opaque black plastic. As pipefish are visual feeders (Ryer \& Boehlert 1983 pers. obs.), amphipods were thus given an acclimation period without risk of predation.

Trials were conducted individually and serially, allowing direct observation of all predator-prey interactions. After removal of the aquarium cover, a trial began and data recording was initiated when a fish first attacked an amphipod, or positioned itself for attack. A trial was continued until: fish stopped foraging (see description of foraging behavior below), the trial exceeded $20 \mathrm{~min}$, or ca $25 \%$ of the amphipods were consumed. Hence, prey densities and distributions did not change greatly during a trial, and fish did not become satiated. Trials where fish did not display typical foraging behavior (ca $20 \%$ of attempted trials) were discarded and repeated. Pipefish foraging behavior is characteristic and entails slow swimming or snakelike movements along the bottom with frequent pauses (up to $1 \mathrm{~min}$ ), during which the head is slowly moved up and down and side to side. This appears to be methodical examination of the surroundings, with examination of individual shoots for prey. Atypical behavior, for which treatments were discarded, consisted of either rapid swimming up and down facing the aquaria walls, or lying motionless on the bottom or suspended in the canopy. In both atypical behaviors amphipods were ignored.

Fish were observed from a distance of $50 \mathrm{~cm}$ in a darkened room (aquarium overhead light only) and did not appear to respond to the observer's presence, eliminating the need for a blind. Data were entered with the remote keyboard of a microcomputer running an event-recording program. An encounter between fish and amphipod was defined by the simultaneous fixation by the fish of both eyes upon the amphipod. An attack was defined by attempted consumption of an amphipod through a forward thrust of the head with a concurrent inward sucking through the snout. An attack was considered successful when the amphipod was captured and swallowed.

Statistical analysis. Four dependent variables were quantified: (1) Encounter Rate - the number of amphipods encountered per min (not including time spent in positioning, pursuit, or handling of prey); (2) Attack Probability - the proportion of encountered amphipods which were attacked; (3) Success Probability - the proportion of attacked amphipods which were captured and consumed; (4) Consumption Rate - the number of amphipods consumed per min, inclusive of positioning, pursuit, and handling time.

Examination of normal deviates plotted against ranked observations (rankit plot; Sokal \& Rohlf 1981) indicated that dependent variables were normally distributed. Attack and success probabilities were homoscedastic (Cochrans's C-test; Sokal \& Rohlf 1981). Natural $\log$ transformation $(\ln [x+1])$ of encounter rates resulted in homoscedasticity. Despite use of several common transformations ( $\ln , \log$, sqrt, arcsin), consumption rates remained heteroscedastic. Attack probabilities, success probabilities, and transformed encounter rates were analysed by analysis of variance (ANOVA; Sokal \& Rohlf 1981), with habitat, fish size, and prey size as independent variables. As dictated by results of ANOVAs, appropriate multiple comparison of means were conducted using the Student-Newman-Keuls procedure (SNK), controlling for experiment-wide error (Underwood 1981). Consumption rate data were separated into 2 data sets by fish size. Natural log-transformed consumption rates for small and large fish were homoscedastic ( $C$-test), and were analysed separately by ANOVA, and where appropriate, SNK comparisons.

Examination of residuals for all dependent variables indicated that no fish which was used more than once 
showed a tendency toward consistently high or low response. I therefore conclude that the occasional reuse of fish resulted in no significant experimental bias. For any statistical test, the null hypothesis of no effect was rejected at $p \leq 0.05$.

\section{RESULTS}

\section{General foraging behavior}

When aquarium covers were removed at the initiation of a trial fish were lying motionless on the bottom or suspended within the artificial eelgrass. After several seconds to several minutes fish became active. Conversely, amphipods appeared to have been active during the acclimation period, as many were exposed on the bottom or swimming. These quickly redistributed themselves to the spaces between basal portions of blades by the time fish began to forage.

Detection of an amphipod involved sudden fixation of both eyes upon the amphipod and a rapid closing of the distance between fish and prey. This was followed by a variable period of positioning ( 1 to $20 \mathrm{~s}$ ), as the fish examined the amphipod and attempted to get within striking distance (ca $1 \mathrm{~cm}$ ). Sometime fish backed away from amphipods, but returned to initiate an attack. Attack consisted of a quick thrusting forward of the head to bring the mouth to within 2 to $6 \mathrm{~mm}$ of the amphipod, combined with a rapid expansion of the buccal and opercular chambers. The propensity to attack seemed to depend upon the amphipod's degree of physical exposure. Amphipods nestled deep between the basal portions of grassblades were often scrutinized and abandoned, while exposed amphipods were more often attacked. Amphipod movement also appeared to result in a higher probability of attack. Approach and attack positioning by pipefish did not appear to result in any change in amphipod behavior, and amphipods did not attempt to escape until attacked. No obvious differences in behavior between amphipod sizes was observed.

\section{Encounter, attack, success and consumption}

ANOVA indicated a significant 3-way interaction (Table 1) between habitat, fish size, and prey size for encounter rates (encounters $\mathrm{min}^{-1}$ ). Small fish showed a trend for increasing encounter rate with increasing prey size (Fig. 1), although this was not significant in either habitat (SNK). There was no significant difference in encounter rates between prey sizes for large fish in the wide leaf (high complexity) habitat, but a significant effect in the narrow leaf (low complexity)
Table 1. Summary of analysis of variance (ANOVA) for natural $\log$ transformed $(\ln (x+1))$ encounter rates

\begin{tabular}{lrrrr}
\hline Source & SS & df & $F$ & Sig. \\
\hline Habitat & 1.442 & 1 & 32.493 & 0.000 \\
Fish Size & 1.377 & 1 & 31.026 & 0.000 \\
Prey Size & 0.391 & 2 & 4.401 & 0.016 \\
Hab $\times$ Fish & 0.706 & 1 & 15.907 & 0.000 \\
Hab $\times$ Prey & 0.093 & 2 & 1.052 & 0.355 \\
Fish $\times$ Prey & 0.038 & 2 & 0.430 & 0.652 \\
Hab $\times$ Fish $\times$ Prey & 0.378 & 2 & 4.263 & 0.019 \\
Unexplained & 2.663 & 60 & & \\
\hline
\end{tabular}

\section{Large Fish Small Fish}

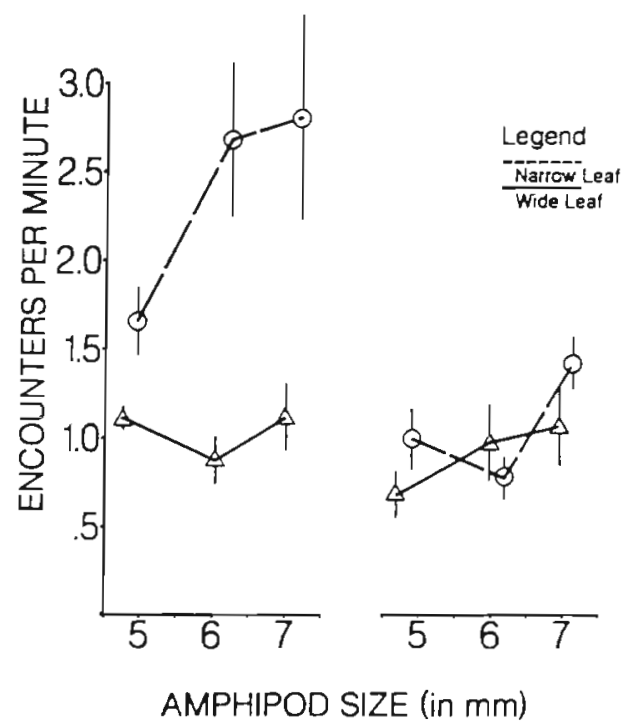

Fig. 1. Mean ( \pm 1 standard error) encounter rates (encounters $\mathrm{min}^{-2}$ ) of pipefish with amphipods across 2 habitats (wide and narrow leaf), 2 fish sizes, and 3 amphipod sizes

habitat, where encounter rates for small amphipods were significantly lower than for either medium or large amphipods (SNK). Small fish in both habitats, and large fish in the wide leaf habitat, showed encounter rates of comparable magnitude. These fish reacted to amphipods at short distances $(<10 \mathrm{~cm})$, and foraged in a slow deliberate manner. Large fish in the narrow leaf habitat had higher encounter rates and reacted to amphipods at greater distance $(<15 \mathrm{~cm})$.

For attack probability (attacks encounter ${ }^{-1}$ ) ANOVA indicated significant interactions between habitat and fish size, and habitat and prey size (Table 2). In the wide leaf habitat there was no difference between attack probabilities for the 2 fish sizes (Fig. 2); however, large fish attack probabilities were significantly greater than those for small fish in the narrow leaf habitat (SNK). There were no significant differences in attack probabilities for the 3 amphipod sizes in either 
Table 2. Summary of analysis of variance (ANOVA) for attack probabilities

\begin{tabular}{|lcccc|}
\hline Source & SS & df & $F$ & Sig. \\
\hline Habitat & 0.123 & 1 & 3.996 & 0.050 \\
Fish Size & 0.194 & 1 & 6.310 & 0.015 \\
Prey Size & 0.062 & 2 & 1.012 & 0.369 \\
Hab $\times$ Fish & 0.213 & 1 & 6.948 & 0.011 \\
Hab $\times$ Prey & 0.265 & 2 & 4.324 & 0.018 \\
Fish $\times$ Prey & 0.191 & 2 & 3.105 & 0.052 \\
Hab $\times$ Fish $\times$ Prey & 0.124 & 2 & 2.026 & 0.141 \\
Unexplained & 1.841 & 60 & & \\
\hline
\end{tabular}

Large Fish Small Fish

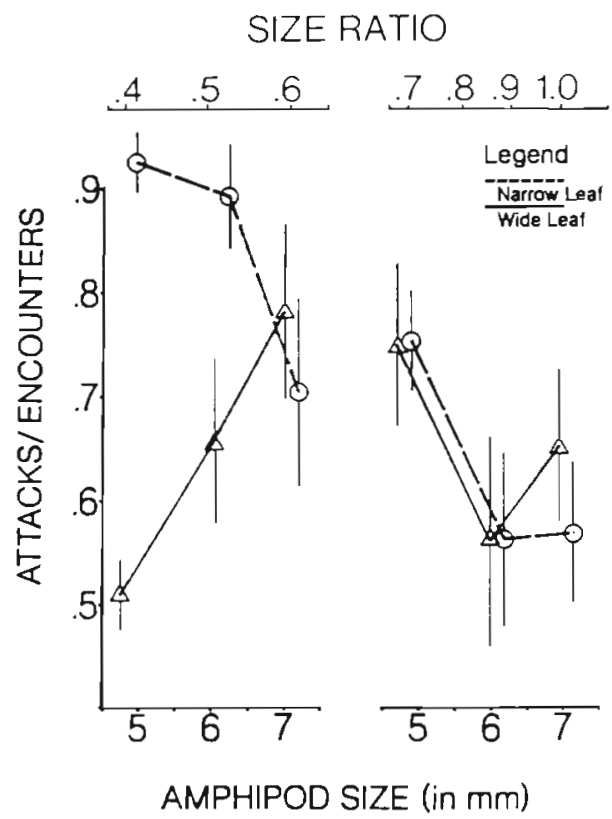

Fig. 2. Mean ( \pm 1 standard error) attack probability (attacks encounter ${ }^{-1}$ ) for large and small fish in the 2 habitats

habitat (SNK), although there was a trend for attack probability to be negatively associated with prey size in the narrow leaf habitat. The most striking aspect of Fig. 2 is the response to habitat exhibited by large fish. Small fish had the same response to both habitats. Large fish attack probability increased with prey size in the wide leaf habitat, but decreased with increasing prey size in the narrow leaf habitat. A relative size ratio (prey size/fish snout length [measured from mouth to corner of eyej) was used to standardize various amphipod-fish combinations. In the narrow leaf habitat attack probability decreased with increasing size ratio. In the wide leaf habitat highest attack probabilities occurred at intermediate size ratios (large amphipod/ large fish, small amphipod/small fish).

ANOVA indicated significant interactions between
Table 3. Summary of analysis of variance (ANOVA) for success probabilities

\begin{tabular}{|lcrrr|}
\hline Source & SS & df & $F$ & Sig. \\
\hline Habitat & 0.002 & 1 & 0.053 & 0.818 \\
Fish Size & 0.978 & 1 & 25.076 & 0.000 \\
Prey Size & 1.083 & 2 & 13.885 & 0.000 \\
Hab $\times$ Fish & 0.037 & 1 & 0.937 & 0.337 \\
Hab $\times$ Prey & 0.337 & 2 & 4.322 & 0.018 \\
Fish $\times$ Prey & 0.546 & 2 & 6.998 & 0.002 \\
Hab $\times$ Fish $\times$ Prey & 0.029 & 2 & 0.375 & 0.689 \\
Unexplained & 2.340 & 60 & & \\
\hline
\end{tabular}

\section{Large Fish Small Fish}

\section{SIZE RATIO}

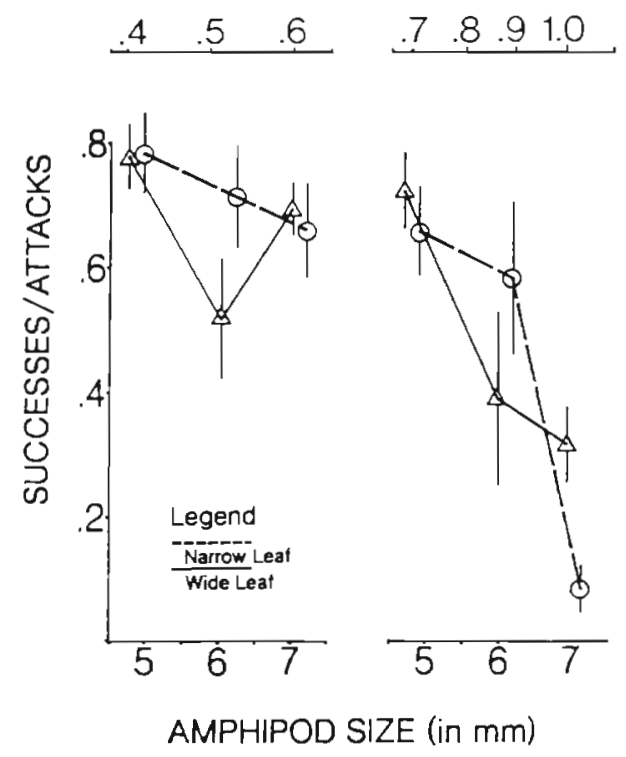

Fig. 3. Mean ( \pm 1 standard error) success probability (successes attack ${ }^{-1}$ ) for large and small fish in the 2 habitats

habitat and prey size, and fish size and prey size (Table 3) for success probability (successes attack ${ }^{-1}$; Fig. 3). In the wide leaf habitat there was greater success in attacks upon small amphipods, as opposed to medium and large amphipods, and lower success upon medium, as opposed to large and small amphipods (SNK). In the narrow leaf habitat success was lower for large than for either medium or small amphipods. Large fish showed no significant decrease in success over the 3 amphipod sizes (SNK). Small fish success was significantly lower for large amphipods, as opposed to either small or medium sized amphipods (SNK). Overall, success probability decreased with increasing relative size ratio.

For consumption rates (amphipods $\mathrm{min}^{-1}$ ) ANOVA for large fish indicated a significant effect of habitat 
Table 4. Summary of analysis of variance (ANOVA) of natural log transformed (In $(x+1))$ consumption rates, for large and small fish

\begin{tabular}{|lrrrr|}
\hline Source & SS & df & $F$ & Sig. \\
\hline Large fish & & & & \\
Habitat & 1.662 & 1 & 27.506 & 0.000 \\
Prey Size & 0.020 & 2 & 0.163 & 0.850 \\
Unexplained & 0.270 & 2 & 2.231 & 0.125 \\
& 1.812 & 30 & & \\
Small fish & & & & \\
Habitat & 0.001 & 1 & 0.107 & 0.746 \\
Prey Size & 0.261 & 2 & 9.772 & 0.001 \\
Hab $\times$ Prey & 0.055 & 2 & 2.068 & 0.144 \\
Unexplained & 0.401 & 30 & & \\
\hline
\end{tabular}

Large Fish Small Fish

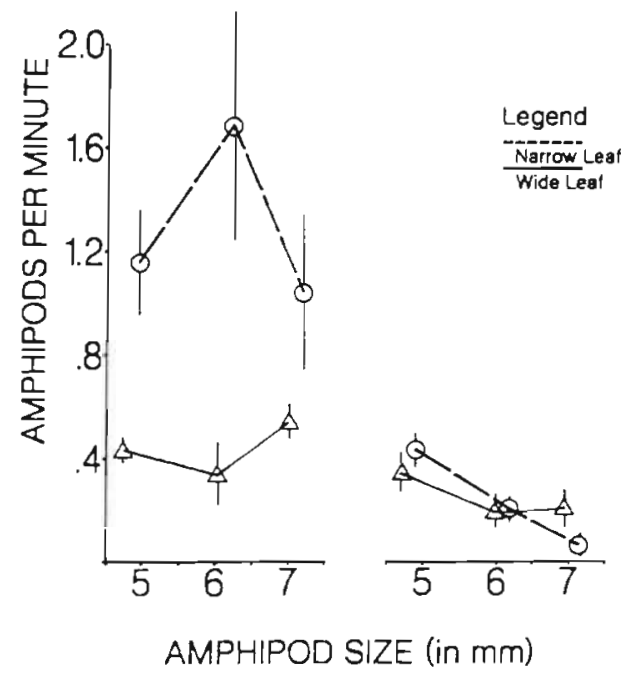

Fig. 4. Mean ( \pm 1 standard error) amphipod consumption rates (amphipods eaten $\mathrm{min}^{-1}$ ) for large and small fish in the 2 habitats

(Table 4). Large fish had higher consumption rates in the narrow than in the wide leaf habitat (Fig. 4). ANOVA for small fish indicated a significant effect of prey size. Large amphipods were consumed significantly less than either medium or small amphipods, and small amphipods were consumed significantly more than either medium or large amphipods (SNK).

\section{DISCUSSION}

The rate at which predators consume prey is a function of prey encounter, probability of subsequent attack, and probability of successful consumption. In turn, each of these may be dependent upon predator size, prey size, habitat complexity, and their interaction with predator and prey behavior and prey palatability. Other studies have examined how vegetation density affects overall predator efficiency (Heck \& Thoman 1981, Savino \& Stein 1982, Stoner 1982), but have not necessarily provided an understanding of how habitat complexity affects the fundamental, more mechanistic aspects of foraging. The artificial vegetation utilized in this study was representative of intermediate eelgrass densities encountered during summer in the lower Chesapeake Bay. Caution should be exercised in generalizing conclusions to conditions of higher seagrass density, or to other submerged aquatic species. However, intermediate or sparse vegetation is often characteristic of the ecotone between vegetated and unvegetated bottoms, where species that are both predators and prey frequently congregate (Holt et al 1983). These zones of transition may play an important role in predator-prey interactions in vegetated habitats.

As predicted, there was a general trend, although not significant for all fish-habitat combinations, for encounter rate to increase with amphipod size. Contrary to expectations, encounter rates for small fish showed no response to increased habitat complexity. Apparently, neither decreased ability to detect amphipods at distance, due to impingement upon fish reactive field volumes ( $R F V s$ ), nor increased quality of hiding places for amphipods were important. Encounter rates for large fish showed a distinct response to altered habitat complexity. The higher rate of encounter in the low complexity habitat did not appear to be the result of increased search speed. Instead, these fish seemed to react to amphipods at greater distance. I suggest that greater eye size resulted in greater reactive distance. Increase in eye size results in a larger retinal image, and since decrease in retinal resolving power in fish is proportionately less than the increase in retinal image size, visual acuity increases with increasing eye size (Northmore et al. 1978). In the wide leaf habitat visual interference from vegetation may have reduced the RFV of large fish to a size comparable to the RFV of small fish, while reduced visual interference in the narrow leaf habitat allowed large fish to utilize their greater distance vision. It is also possible that amphipods were more conspicuous at distance when positioned between the narrow, as opposed to large blades. Stoner (1982) found amphipods to be more readily detected by pinfish on the narrow blades of Halodule wrightii than on wider blades of Thalassia testudinum.

An alternative explanation of these results involves size-dependent risks, as perceived by pipefish, associated with foraging in the 2 habitats. Small fish, possibly at greater risk from predators, might forage more slowly than large fish in the narrow leaf habitat, adopt- 
ing a strategy of 'movement minimization' (Pough \& Andrews 1985), as doing so would make them less conspicuous. As no pipefish-predators were used in this experiment, this would imply that pipefish have a fairly rigid repertoire of behavior This implication does not conform to the emerging pattern of behavioral plasticity demonstrated by fish (Gilliam \& Fraser 1987).

Probabilistic attack may depend upon a number of factors: hunger level (Bence \& Murdoch 1986), prey profitability (Werner \& Hall 1974), palatability, apparent size of prey (O'Brien et al. 1976), and prey motion (Zaret 1980a). I sought to minimize the effects of changing hunger level (i.e. satiation) through uniform pre-trial starvation and by keeping experimental trials short in duration. I assume that profitability is determined by amphipod size, which I controlled, and that palatability is independent of size. I further assume that apparent size, as a criterion for selection between simultaneously encountered prey, is not relevant in the context of this study. Amphipod densities were low, so that simultaneous encounters did not occur often. When they did, multiple amphipods were encountered upon a single shoot, and being of the same size, probably had comparable apparent sizes. In such instances I noted that amphipod motion often drew attack from pipefish. Main (1985) also reported that both Syngnathus floridae and Lagodon rhomboides concentrated attacks upon moving, as opposed to motionless prey.

If foraging tactics are contributors to fitness, and natural selection acts upon them, predators should develop behaviors that eliminate or minimize unsuccessful attacks. The predictions of this study, with respect to attack probabilities, did not match the observed patterns. There was an interaction between habitat and fish size that determined the effect of amphipod size upon attack probability. I suggest that probabilistic attack was determined by 2 interacting and opposing factors: the relative size of amphipods and fish, and the relative size-dependent ability of pipefish to extract amphipods from available refugia. Narrow leaves afforded little protection to amphipods regardless of pipefish size, as the refuge space between leaves was small, leaving amphipods vulnerable to attack from either side. In the absence of effective refugia, increased amphipod size was the only deterrent to attack from pipefish, and probabilistic attack decreased with increasing size of amphipods relative to pipefish size. In the wide leafed habitat small fish were able to get their mouths between leaves to attack small amphipods, again leaving increased amphipod size as the major deterrent to attack. Wide leaves afforded greater protection from attack by large fish when amphipods were small: large fish could not get their mouths close enough to attack small amphipods nestled far down between grassblades, whereas large amphipods could not get as far down between leaves, or were more exposed from the sides, and were thus more vulnerable. This resulted in a positive relationship between amphipod size and attack probability for large fish in the wide leaf habitat. Similar results were obtained by Stein (1977), where small crayfish were preferentially consumed by smallmouth bass on sand substrates, while intermediate size crayfish were consumed on pebble substrates. As in the present study, prey that were small relative to fish were able to decrease their vulnerability by retreating into the spaces between structure, taking advantage of sizedependent refuges.

For the high complexity habitat there may be a relative size (amphipod/fish size) threshold below which attack probabilities decrease as amphipods become less vulnerable due to refugia use, and above which attack probability also decreases as amphipods become less vulnerable due to larger relative size. This would give rise to a humped distribution of attack probabilities, with peak probability of attack at intermediate size ratios. Only 2 fish sizes and 3 amphipod sizes were used in this study. The prey-predator size ratios for the 2 fish sizes were disjunct (i.e. no overlap), and it could be argued that the observed results are due to distinct behavioral differences between the 2 fish sizes, irrespective of relative size considerations. Testing this hypothesis would require a greater number of both predator and prey sizes, for which relative size ratios overlap.

Pipefish appear able to modify their foraging tactics as reflected by attack probabilities in response to changes in habitat complexity. As a result there was no overall effect of habitat upon success. With habitat-related effects factored out by behavior, the probability of predator success appears to have been determined by escape capabilities of prey and mechanical limitations such as mouth gape (Zaret 1980b, Scott \& Murdoch 1983). Many of the prey species consumed by Syngnathus fuscus have a broad range of sizes, and mouth gape puts an upper limit upon prey sizes consumed in the field (Ryer \& Orth 1987). In this study, larger amphipods, when attacked, often were not sucked fully into the mouth and escaped by rapidly swimming away. Prey size had less of an effect upon large fish than small fish. This indicates that the relationship between relative size and success may be nonlinear: success decreasing slowly at first with increasing prey size, and then more rapidly as prey approach the maximum the fish is capable of consuming.

While this study was not designed to study amphipod behavior, several observations were noteworthy. Gammarus spp. appeared to be unaware of, or did not respond to fish until attacked. Main (1987) demonstrated that a marine shrimp, Tozeuma carolinense, 
displays elaborate avoidance behaviors in response to approaching predators. Yet, avoidance behavior need not occur at the time of encounter Both vertebrate (Gilliam \& Fraser 1987, Newman \& Caraco 1987, Petranka et al. 1987) and invertebrate prey (Stein \& Magnuson 1976, Zaret \& Suffern 1976) modify their distributions and/or foraging behaviors to avoid predation. Since most amphipods were between basal portions of blades, microhabitat preference for these locations during daylight hours may be an adaptation to decrease susceptibility to visual predators. Wellborn \& Robinson (1987) demonstrated that odonate larvae positioned in the axil areas of Sagittaria platyphylla plants are less susceptible to predation by sunfish than larvae exposed on leaves. For amphipods, microhabitat selection and refuge utilization may be as important in mediating predation as post-encounter avoidance behaviors.

Vegetation enhances the escape capabilities of prey by allowing them to get out of the predator's visual field (Main 1987). I have observed pipefish to pursue and repeatedly attack fleeing amphipods in aquaria without any vegetation, but in the 2 vegetated habitats examined here, pipefish rarely pursued amphipods after an unsuccessful attack. For mobile prey, the ability to hide, or to escape a pursuing predator by placing visual obstructions in its path, may be an important effect of increased habitat complexity.

Several authors (Heck \& Orth 1980, Stoner \& Lewis 1985) have discussed the qualitative and quantitative aspects of vegetational characteristics that constitute complexity, and how these affect community organization and trophic dynamics. While caution should be exercised in extrapolating the findings of this study to field conditions, they do suggest that structural complexity must be considered in the context of the relative sizes of predator, prey, and refugia. Individual prey, even though they are of the same size, may be perceived as fundamentally different by predators, as a result of their utilization of available microhabitats. Pipefish appear able to judge prey accordingly, and adjust foraging tactics to match environmental constraints. Finally, the component approach undertaken here, considering encounter rate, and attack and success probabilities, rather than overall consumption, may provide a clearer understanding of the mechanisms of interaction between predators and prey in structurally complex habitats.

Acknowledgements. I thank Robert Orth, Richard Wetzel, Rom Lipcius, Mark Lukenbach, David Stillwell, and 2 anonymous reviewers for helpful comments on the manuscript. Thanks to the students and staff at VIMS for help in the lab and field. This is Contribution No. 1469 from the Virginia Institute of Marine Science of the College of William and Mary.

\section{LITERATURE CITED}

Bell, S. S. Coen, L. D. (1982). Investigations on epibenthic meiofauna. II. Influence of microhabitat and macroalgae on the abundance of small invertebrates on Diopatra cuprea [(Bosc) (Polychaeta: Onuphidae)] tube caps in Virginia. J. exp. mar. Biol. Ecol 61: 175-188

Bence, J. R., Murdoch, W. W. (1986). Prey size selection by the mosquitofish: relation to optimal diet theory. Ecology 67 : 324-336

Coull, B. C., Wells, J. B. J. (1983). Refuges from fish predation: experiments with phytal meiofauna from the New Zealand rocky intertidal. Ecology 64: 1599-1609

Crowder, L. B., Cooper, W. E. (1982). Habitat structural complexity and the interaction between bluegills and their prey. Ecology 63: 1802-1813

Dawson, C. E. (1982). Snygnathidae. In: Bohlke, J. E. (ed.) Fishes of the western North Atlantic, Part 8 . Sears Foundation for Marine Research, Yale Univ., New Haven, p. 76-82

Fredette, T J., Diaz, R. J. (1986). Life history of Gammarus mucronatus Say (Amphipoda: Gammaridae) in warm temperate estuarine habitats, York River, Virginia. J. Crust. Biol. 6: 57-78

Gause, G. F. (1934). The struggle for existance. Hafner, New York

Gilliam, J. F., Fraser, D. F. (1987). Habitat selection under predation hazard: test of a model with foraging minnows. Ecology 68: 1856-1862

Heck, K. L., Orth, R. J. (1980). Seagrass habitats: the role of habitat complexity, competition and predation in structuring associated fish and motile macroinvertebrate assemblages. In: Kennedy, V S. (ed.) Estuarine perspectives. Academic Press, New York, p. 449-464

Heck, K. L. Jr, Thoman, T. A. (1981). Experiments on predatorprey interactions in vegetated aquatic habitats. J. exp. mar. Biol. Ecol. 53: 125-134

Holt, S. A., Kitting, C. L., Arnold, C. R. (1983). Distribution of young red drums among different sea-grass meadows. Trans. Am. Fish. Soc. 112: 267-271

Homziak, J., Fonseca, M. S., Kenworthy, W J. (1982). Macrobenthic community structure in a transplanted eelgrass (Zostera marina) meadow. Mar. Ecol. Prog. Ser. 9: 211-221

Lipcius, R. N., Hines, A. H. (1986). Variable functional responses of a marine predator in dissimilar homogeneous microhabitats. Ecology 67: 1361-1371

Main, K. L. (1985). The influence of prey identity and size on selection of prey by two marine fishes. J. exp mar. Biol Ecol. 88: 1.45-152

Main, K. L. (1987). Predator avoidance in seagrass meadows: prey behavior, microhabitat selection, and cryptic coloration. Ecology 68: 170-180

Marinelli, R. L., Coull, B. C. (1987). Structural complexity and juvenile fish predation on meiobenthos: an experimental approach. J. exp mar. Biol. Ecol. 108: 67-81

Nagle, J. S. (1968). Distribution of epibiota of macroepibenthic plants. Contr mar Sci. 13: 105-144

Newman, J. A., Caraco, T (1987). Foraging, predation hazard and patch use in gray squirrels. Anim. Behav. 35: $1804-1813$

Northmore, D., Volkmann, F. C., Yager, D. (1978). Vision in fishes: color and pattern. In: Mostorsky, D. I. (ed.) The behavior of fish and other aquatic animals. Academic Press, New York, p. 79-136

O'Brien, W. J., Slade, N. A., Vinyard, G. L. (1976). Apparent size as the determinant of prey selection by bluegill sunfish (Lepomis macrochinus). Ecology 57. 1304-1310

Orth, R. J. (1977). The importance of sediment stability in 
seagrass communities. In: Coull, B. C. (ed.) Ecology of marine benthos. University of South Carolina Press, Columbia, p. 281-300

Orth, R. J., Moore, K. A. (1986). Seasonal and year-to-year variations in the growth of Zostera marina L. (eelgrass) in the lower Chesapeake Bay. Aquat. Bot. 24: 335-341

Paine, R. T. (1966). Food web complexity and species diversity. Am. Nat. 100: 65-75

Petranka, J. W., Kats, L. B., Sih, A. (1987). Predator-prey interactions among fish and larval amphibians: use of chemical cues to detect predatory fish. Anim. Behav. 35: 420-425

Pough, F. H., Andrews, R. M. (1985). Energy costs of subduing and swallowing prey for a lizard. Ecology $66: 1525-1533$

Russo, A. R. (1987). Role of habitat complexity in mediating predation by the gray damselfish Abudefduf sordidus on epiphytal amphipods. Mar. Ecol. Progr. Ser. 36: 101-105

Ryer, C. H., Boehlert, G. W. (1983). Feeding chronology, daily ration, and the effects of temperature upon gastric evacuation in the pipefish, Syngnathus fuscus. Environ. Biol. Fish. 9: 301-306

Ryer, C. H., Orth, R. J. (1987). Feeding ecology of the northern pipefish, Syngnathus fuscus, in a lower Chesapeake Bay seagrass community. Estuaries 10:330-336

Savino, J. F., Stein, R. A. (1982). Predator-prey interaction between largemouth bass and bluegills as influenced by simulated, submersed vegetation. Trans. Am. Fish. Soc. 111: 255-266

Scott, M. A., Murdoch, W. W. (1983). Selective predation by the backswimmer, Notonecta. Limnol. Oceanogr. 28: 352-366

Smith, L. D., Coull, B. C. (1987). Juvenile spot (Pisces) and grass shrimp predation on meiobenthos in muddy and sandy substrata. J. exp. mar. Biol. Ecol. 105: 123-136

Sokal, R. R., Rohlf, F. J. (1981). Biometry. W. H. Freeman and Co., San Francisco

Stein, R. A. (1977). Selective predation, optimal foraging, and the predator-prey interaction between fish and crayfish. Ecology 58: 1237-1253

Stein, R. A., Magnuson, J. J. (1976). Behavioral response of crayfish to a fish predator Ecology $57: 571-581$
Stoner, A. W. (1980). Perception and choice of substratum by epifaunal amphipods associated with seagrasses. Mar. Ecol. Prog. Ser, 3: 105-111

Stoner, A. W. (1982). The influence of benthic macrophytes on the foraging behavior of pinfish, Lagodon rhomboides (Linnaeus). J. exp. mar. Biol. Ecol. 58: 271-284

Stoner, A. W., Lewis, F. G. (1985). The influence of quantitative and qualitative aspects of habitat complexity in tropical sea-grass meadows. J. exp. mar Biol. Ecol. 94 : $19-40$

Underwood, A. J. (1981). Techniques of analysis of variance in experimental marine biology and ecology. Oceanogr. mar. Biol. A. Rev, 19: 513-605

van Dolah, R. F. (1978). Factors regulating the distribution and population dynamics of the amphipod Gammarus palustris in an intertidal salt marsh community. Ecol. Monogr. 48: $191-217$

Ware, D. M. (1972). Predation by rainbow trout (Salmo gairdneri): the influence of hunger, prey density, and prey size. J. Fish. Res. Bd Can. 29: 1193-1201

Wellborn, G. A., Robinson, J. V. (1987). Microhabitat selection as an antipredator strategy in the aquatic insect Pachydiplax longipennis Burnmeister (Odonata: Libellulidae). Oecologia (Berl.) 71: 185-189

Werner, E. E., Hall, D. J. (1974). Optimal foraging and the size selection of prey by bluegill sunfish (Lepomis macrochirus). Ecology 55: 1042-1052

Zaret, T. M. (1980a). The effect of prey motion on planktivore choice. In: Kerfoot, W C. (ed.) Evolution and ecology of zooplankton communities. University Press of New England, Hanover, New Hampshire, p. 594-603

Zaret, T M. (1980b). Predation in freshwater communities. Yale University Press, New Haven

Zaret, T. M., Kerfoot, W. C. (1975). Fish predation on Bosmina longirostris: body-size selection versus visibility selection. Ecology 56: 232-237

Zaret, T. M., Suffern, J. S. (1976). Vertical migration in zooplankton as a predator avoidance mechanism. Limnol. Oceanogr 21: 804-813 